\title{
Exploring natural capital using bibliometrics and social media data
}

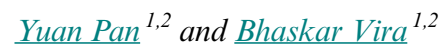

\begin{abstract}
Research and interest into natural capital, i.e., the stock of the world's natural resources, is increasing as it links humans with nature within a social-ecological system, contributing to ecosystem sustainability. We collected publication data for 300 natural capital papers to explore academic networks and research trends. We used Twitter to collect 14,193 tweets about natural capital over nine months. Analyzing publication data shows three main research clusters, but few coauthorships between the clusters. The results show substantial international coauthorships, and the dominance of American and British academics as coauthors. Analyzing Twitter data, we identified a small community of key users that tweet about natural capital frequently. We found that a range of words is used in tweets about natural capital and the overall sentiment of tweets is positive. For both types of data, "ecosystem services" and "biodiversity" are keywords associated with natural capital. Our results have identified key communities of natural capital researchers, but highlight a potential disconnect between research clusters that needs to be addressed. Current communities surrounding natural capital in academia and on Twitter are relatively exclusive and small.
\end{abstract}

Key Words: bibliometrics; citation analysis; natural capital; network analysis; social media; Twitter

\section{INTRODUCTION}

Natural capital refers to the global stock of natural resources (Guerry et al. 2015). From natural capital, human society receives many irreplaceable and important benefits that are termed ecosystem services. Humans can also negatively affect ecosystem services through land use changes or chemical pollution (Mace et al. 2012). The relationship between stocks of natural capital and flows of ecosystem services is nonlinear and not yet completely understood. Although closely connected, both concepts are independently important for considering humanity's relationships with nature, with natural capital drawing attention to the stocks and asset values that derive from natural systems, while ecosystem services are typically seen as specific flows of benefits (Vira and Adams 2009).

Natural capital research not only crosses different academic disciplines, but interest in natural capital has extended to businesses and policy makers (Peiffer and Haustermann 2018). For example, Unilever (a transnational consumer goods company) has investigated its natural capital impacts under the sustainable living agenda (Unilever 2018). The UK 25 Year Environment Plan has emphasized the need to adopt a natural capital approach (Defra 2018). Natural capital protection requires knowledge from the natural and social sciences (Costanza and Kubiszewski 2012), as well as engagement with decision makers in the public and private sectors.

There is rising interest in transdisciplinary work within academic research, where disciplinary boundaries become more blurred and researchers create a new transdiscipline using a common framework (Klein 2008). To be effective, transdisciplinary research requires researchers to understand concepts and language from different disciplines and develop a new shared understanding. This is a legitimate aspiration for natural capital research, with its existing foundations in the ecological sciences, economics, and the social sciences (Mitchell 2005). In this applied and transdisciplinary context, it is important to investigate the epistemic framing of natural capital within academic publications. Furthermore, we need to explore how natural capital is understood and conceptualized outside academic publications to consider whether there is an emergent community of practice around this term.

We have used two methods of data collection to explore natural capital: bibliometrics and social media. Bibliometrics is the statistical analysis of written publications that can assess research impacts (Branch 2013). It has risen in popularity because the numbers produced by bibliometrics can be easily assessed, whereas traditional peer review opinions are more difficult to compare (Bornmann and Mutz 2015). Many institutions assess researchers by the quantity and quality of their published research. Using databases such as the Web of Science or Scopus, bibliometrics data can be easily obtained and statistically analyzed for different disciplines (Mongeon and Paul-Hus 2016). It is a useful method for assessing a field of research within academic publications, and has recently been used to assess networks of knowledge production and epistemic communities (Corbera et al. 2016).

It is also important to investigate how natural capital is portrayed outside academic publications, especially within the wider public discourse. One potential method is to analyze the use of social media, especially by people in professional networks. The increasing use of social media around the world represents an important source of information that can offer significant insights into user views and values (Figueroa-Alfaro and Tang 2016). Social media platforms can generate large datasets over a short period of time. The cost of obtaining social media data is also minimal and researchers can gain data from different regions of the world remotely (Tenerelli et al. 2016).

We chose Twitter to collect social media data because it is a popular platform used by academic researchers, environmental NGOs, professional societies, and institutions to communicate scientific information that can be accessed by nonacademics (Letierce et al. 2010, unpublished manuscript, http://www. johnbreslin.org/files/publications/20100426 webs2010c.pdf). Twitter

${ }^{1}$ University of Cambridge Conservation Research Institute (UCCRI), Cambridge, UK, ${ }^{2}$ Department of Geography, University of Cambridge, Cambridge, UK 
extends far beyond the academic community, providing scientific information to a range of audiences that include the public, policy makers, industries, and the media (Parsons et al. 2014). In addition, Twitter users can express their opinions regarding a subject whereas opinions are rarely expressed in academic publications. Social media data are, however, prone to biases because only a select section of society have access to the internet and use social media platforms (Gliozzo et al. 2016).

Previous studies have looked into the field of ecosystem services research or the citation structure surrounding one particular paper (Costanza and Kubiszewski 2012, Branch 2013, Abson et al. 2014), or there have been studies using Twitter data to investigate climate change issues (Newman 2017, Hopke and Hestres 2018). Although natural capital, i.e., the stock of the world's natural resources, is interlinked to ecosystem services, i.e., the benefits that we receive from nature, they are two different concepts that can often be confused. Because ecosystem services research started earlier than natural capital research, there has been more research on the flow of benefits, i.e., ecosystem services, than on the stock of natural resources, i.e., natural capital (Robinson et al. 2012). In addition, there has been a lack of research into the publication literature surrounding natural capital specifically. To our knowledge, there has been no prior research that explores the concept of natural capital using academic publications and social media data.

Our study aims to evaluate the international academic networks and research trends surrounding natural capital, as well as exploring the portrayal of natural capital and associated user networks on the social media platform Twitter. We address the following key questions: (1) Who are the key researchers or Twitter users regarding natural capital? Are there any key communities or networks? (2) Is natural capital an interdisciplinary research field? (3) Are international collaborations important for advancing natural capital research? (4) How do Twitter users perceive and react to the concept of natural capital?

\section{METHODS}

\section{Bibliometrics}

We performed a search in Clarivate Analytics Web of Science (WoS) for all publications with the term "natural capital" in their title field, from 1900 to 2018 . We only collected publications with natural capital in their titles because this suggests that the focus of their research was on natural capital.

WoS is a scientific citation indexing service that was originally produced by the Institute for Scientific Information (ISI), but it is now managed by Clarivate Analytics. It is the most comprehensive resource, in terms of quality and quantity. Generally, it contains most of the peer-reviewed articles within a research field. Since 2014, WoS has increased to include scholarly books, journal articles, and conference proceedings. In addition, it has increased its coverage of social science journal articles. The databases within WoS span across the natural sciences, social sciences, as well as arts and humanities. In total, WoS consists of seven databases. We chose to use the WoS Core Collection database because it contains the most comprehensive bibliometrics data, including citation reports.

Our search yielded 300 results on 16 August 2018. We downloaded the publication data (e.g., author names, author affiliations, publication years, keywords) and inputted this into $\mathrm{R}$, the open source statistical program. Following this, we converted the file into different matrices to perform network analysis using the bibliometrix package (Aria and Cuccurullo 2017). The constructed matrices included author collaborations (coauthors), cokeywords, and country collaborations. Publication data for all 300 collected papers were used to construct the matrices.

All data were used for network analysis and individually plotted for visualization. In the network plots, the layout is generated using the Fruchterman-Reingold algorithm. For the author collaboration, i.e., coauthors, network plot, only authors from the top 30 cited publications have been plotted and the top 12 authors have been labelled for clearer visualization. This allows the identification of key research clusters and pivotal authors. For the keywords plot, only the top 50 keywords were plotted as a word cloud to avoid overcrowding. For the country collaboration plot, all countries were plotted but only the top 20 countries were labelled for clearer visualization.

\section{Social media data}

Social media data was collected from Twitter over a period of nine months, from 30 April 2018 to 31 January 2019. TAGS (Twitter Archiving Google Sheet), a free Google sheet template app, was used to set up and run automated collection of Twitter data (https://tags.hawksey.info/). TAGS can connect to and access Twitter data by authentication using a personal Twitter account. A detailed tutorial of how to use TAGS is provided on its web site. We collected all tweets with the hashtag "natural capital" or the words "natural capital." The dataset was then imported into the open source statistical program, R, for analysis.

We used the text mining R package, tidytext, to clean the Twitter data (Silge and Robinson 2016). All http elements, emojis, and punctuation was removed from the text data. All letters were converted to lower cases. A list of stop words was loaded from the tidytext package and all stop words were removed from the data. The cleaned text file was saved, and the top 50 keywords were plotted as a word cloud.

We obtained a list of the accounts that tweeted 50 times or more about natural capital. Using the twitte $R$ package in $\mathrm{R}$ (Gentry 2016), a list of their friends was obtained. This was then used to plot a network of the follower relationships between the Twitter accounts using the igraph package (Csárdi and Nepusz 2006). A fast-greedy clustering algorithm was used to detect communities in the dataset. Different communities were plotted using different colors in the network plot.

The tweets dataset was loaded into $\mathrm{R}$ for sentiment analysis using the syuzhet package (Jockers 2015). The package assigned a sentiment score for each tweet, using the National Research Council (NRC) Word-Emotion Association Lexicon. This is a list of English words that can group words into eight basic emotions, as well positive and negative sentiments. The most positive and negative tweets were also identified from the dataset.

\section{RESULTS}

We found 300 publications with the words "natural capital" in their title in the Web of Science databases, as of August 2018. In total, 774 authors have authored a paper on natural capital, with an average of three authors per paper. The number of papers published per year had risen from one paper in 1992 to 28 papers in 2017. The annual growth rate of publications is $12.2 \%$. The 
citation times of publications has been also increasing rapidly. In 1993, the total of times cited per year was only three. Nevertheless, this became 1582 times cited per year in 2017.

In terms of publication numbers, the United States (U.S.) is the most productive country and it is followed by the United Kingdom (UK). The country with highest number of collaborations through coauthorships with other countries is also the U.S., followed by the UK. The top journal for natural capital publication is Ecological Economics. Publications in the Web of Science are split into categories, and the top four categories that "natural capital" publications fall within are environmental sciences, ecology, environmental studies, and economics.

There are three distinctive clusters of researchers in the collaboration network plot. They are made up of ecological or environmental economists in the pink and blue clusters, or soil scientists in the green cluster (Table 1). One academic, Carl Folke, links the pink and blue clusters. Apart from this link, there seem to be little collaboration through coauthorships between the three research clusters (Fig. 1a). Soil scientists in the green cluster coauthor together more frequently within their cluster compared to ecologists and environmental economists in the pink and blue clusters.

Through analyzing the keywords of publications, we find that "natural capital" is a highly interdisciplinary field that encompasses many subject areas. The top five keywords used for publications are ecosystem services, conservation, biodiversity, management, and framework (Fig. 2a). The country collaboration plot demonstrates that most researchers seek coauthorships with American and British researchers for publications (Fig. 3). This suggests that American and British researchers are at the center of natural capital research.

From 30 April 2018 to 31 January 2019, we collected 14,193 tweets that included the term "natural capital." We identified 24 Twitter accounts that tweeted more than 50 times about natural capital during the study period, with Natural Capital Coalition (@NatCapCoalition) being the most frequently tweeting account (Fig. 1b). The top three associated keywords with natural capital tweets were natural, ecosystem services, and nature (Fig. 2b). Nevertheless, there are a wide range of words associated with natural capital and no specific words that dominate the tweets (Fig. 2b). Using sentiment analysis, we found that the overall sentiment score of tweets on natural capital is positive. Around $50 \%$ of the tweets were sorted into the sentiment categories "trust" and "anticipation" (Fig. 4).

\section{DISCUSSION}

\section{Social networks, key researchers, and influencers}

An epistemic community is a network of experts that can provide advice for policy makers or influence policy decisions (Dunlop 2014). Our results have identified an epistemic community formed of three research clusters in natural capital research. The coauthorship structures indicate that natural capital research is contributed to by different researchers, rather than any single prominent researcher. Nevertheless, there may be publications researching "natural capital" without necessarily using the phrase. As a result, we may have missed some publications and have only selected a portion of papers by using the search term "natural capital."
In the pink cluster, the dominant researchers are Gretchen Daily, Stephen Polasky, and Zhiyun Ouyang, who are ecologists, environmental scientists, or environmental economists. Gretchen Daily and Stephen Polasky are the Natural Capital Project cofounders, which is a collaborative project between Stanford University, the Chinese Academy of Sciences (CAS), the University of Minnesota, the Stockholm Resilience Centre, the World Wildlife Fund (WWF), and The Nature Conservancy. Zhiyun Ouyang is a professor at CAS. He appears in the network because the Natural Capital Project now has a longstanding collaboration with the CAS, working on China's national ecosystem assessment. This suggests that collaborations can form because of shared projects and result in longer term international collaborations.

The two dominant researchers in the blue cluster are Rudolf de Groot and Robert Costanza, who are also ecological and environmental economists. Rudolf de Groot is Associate Professor of the Environmental System Analysis Group at Wageningen University and the chair of the Ecosystem Services Partnership, a worldwide network to enhance the science and practical application of ecosystem services. Robert Costanza is the lead author of the highly influential paper that was published in the journal Nature in 1997, titled "The value of the world's ecosystem services and natural capital." Currently, the paper has been cited 21,662 times according to Google Scholar. Rudolf de Groot and Robert Costanza have coauthored several high impact papers in terms of citation counts on natural capital and ecosystem services.

Researchers in the pink and blue clusters are only linked by Carl Folke, who is the science director of the Stockholm Resilience Centre. He is important within natural capital research because he links two different research clusters, by coauthoring with Rudolf de Groot and Robert Costanza. In addition, the Stockholm Resilience Centre now has an international collaboration with the Natural Capital Project. For natural capital research to progress beyond these networks and become transdisciplinary, there needs to be increased linkage between researchers. Therefore, the role of bridging individuals who connect across different disciplines and academic communities is key.

The green cluster is mainly composed of soil scientists that come from the Centre for Ecology and Hydrology $(\mathrm{CEH})$ in the UK. They are collaborating due to their shared interest in soil science and belonging to the same institute. Natural capital originated from the fields of ecology and economics, whereas the field of soil sciences have so far remained separate from natural capital frameworks (Robinson et al. 2012). Soil scientists in the green cluster are attempting to bridge soil science with the ecosystem services and natural capital approach, which requires further progress for improved collaboration with other academic communities.

The author collaboration plot draws attention to potential disconnects in natural capital research, between the three key research clusters. Although tight collaborations within a group allow researchers to concentrate on specific problems, the lack of or few links to other research clusters is a concern for an interdisciplinary field such as natural capital. This can result in 
Table 1. Key authors for academic publications on natural capital, their research areas, and affiliations.

\begin{tabular}{llll}
\hline \hline Cluster & Author & Research area & Affiliation \\
\hline Green & Emett, B. A. & Soil and land use scientist & Centre for Ecology and Hydrology (CEH), Bangor, \\
& & & UK \\
Green & Keith, A. M. & Soil ecologist & CEH, Lancaster, UK \\
Green & Lebron, I. & Soil chemist & CEH, Bangor, UK \\
Green & Robinson, D. A. & Soil scientist & CEH, Bangor, UK \\
Blue & Costanza, R. & Ecological economist & The Australian National University \\
Blue & De Groot, R. & Environmental economist & Wageningen University, The Netherlands \\
Pink & Daily, G. C. & Ecologist/Environmental scientist & Stanford University, USA \\
Pink & Folke, C. & Transdisciplinary environmental scientist & Stockholm Resilience Centre \\
Pink & Li, S. & Ecologist/Environmental economist & Michigan State University, USA \\
Pink & Ouyang, Z. & Ecologist/Ecological economist & Research Center for Eco-Environmental Sciences, \\
& & & Chinese Academy of Sciences, Beijing, China \\
Pink & Polasky, S. & Ecological/Environmental economist & University of Minnesota, USA \\
\hline
\end{tabular}

Fig. 1. (a) Author collaboration network plot with only the top 30 authors visualized, and the top 12 authors labelled for 300 academic publications on natural capital. Lines represent coauthorships in publications. Circle sizes are relative to the number of coauthorships; (b) Key Twitter accounts network plot for accounts that have tweeted > 50 times about natural capital. Lines represent relationships with followers. Circle sizes are relative to the number of followers.

(a) Publications
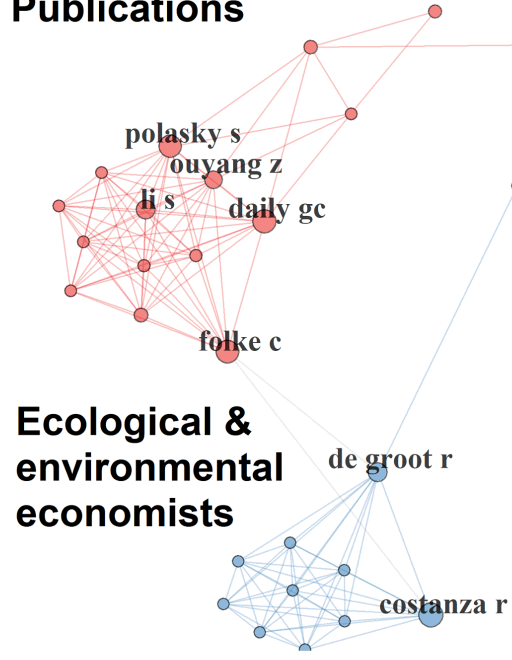

(b) Twitter

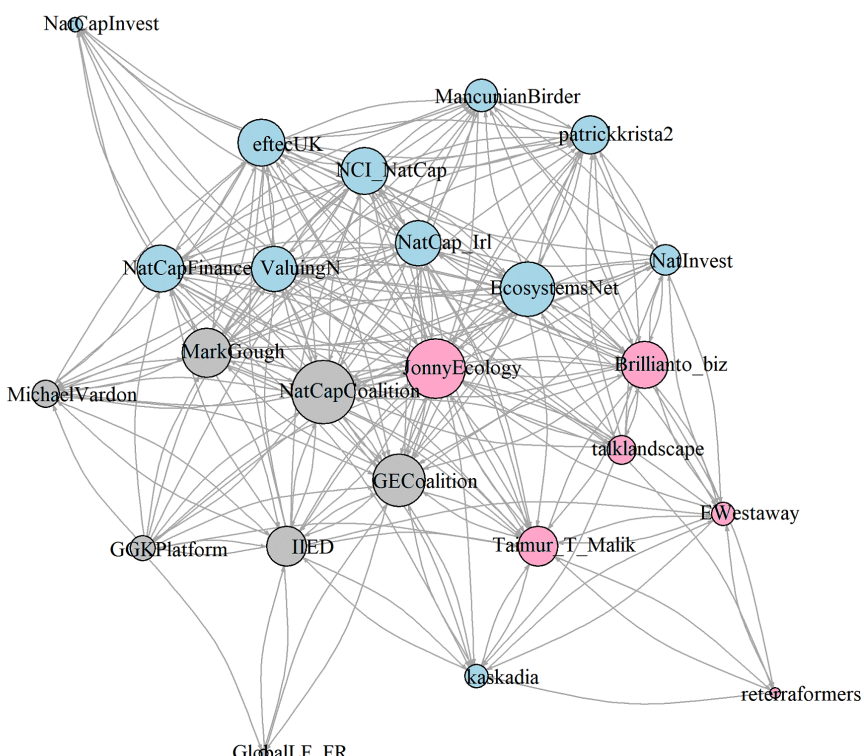


Fig. 2. (a) A word cloud depicting the top 50 keywords that are associated with natural capital publications in Web of Science ( $\mathrm{n}=300$ ); (b) a word cloud depicting the top 50 keywords that have appeared in tweets about natural capital $(n=14,193)$.

\section{(a) Publications}

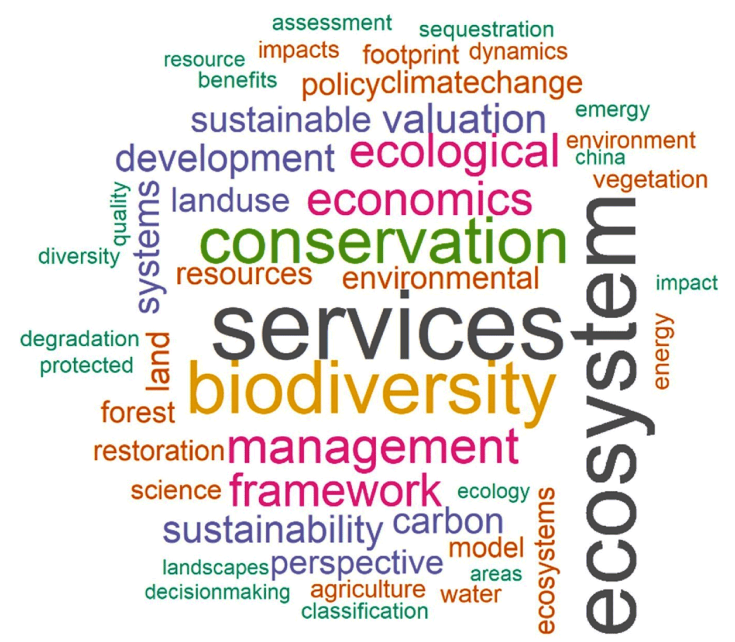

\section{(b) Twitter}

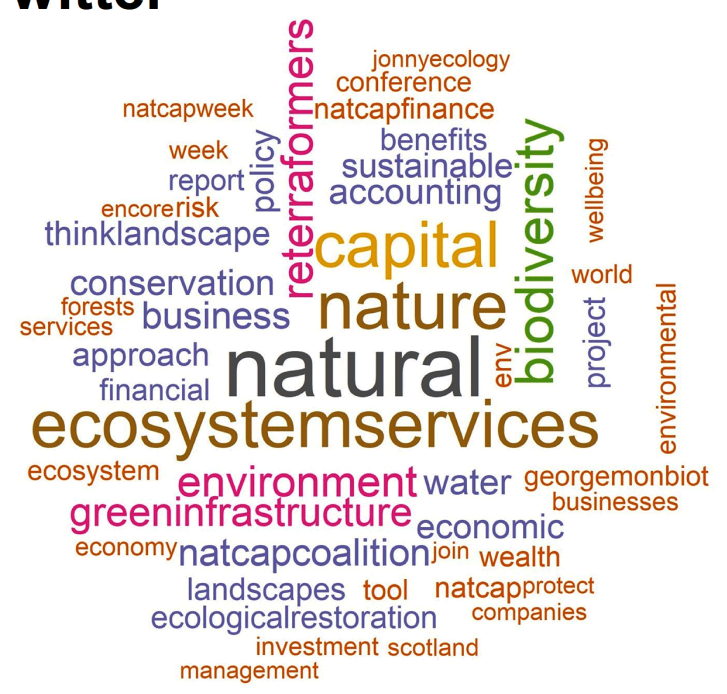

the use of specialized language, jargon, and framing, resulting in communication barriers that might prevent future collaborations (Borrett et al. 2014).

Potential solutions to overcome collaboration barriers include actively seeking out researchers from different research communities for conferences or workshops (Borrett et al. 2014). In particular, providing a balance between natural and social scientists is important. Because the word capital originates from economics, researchers from a natural science background have actively sought increased collaboration with economists, but this has not extended into other relevant social sciences. Extending these networks of intellectual dialogue can help cross traditional
Fig. 3. Country collaboration network plot for 300 academic publications with "natural capital" in their titles. The size of the circle is relative to the number of collaborations between countries. Lines represent collaborations between different countries, i.e., coauthorships.

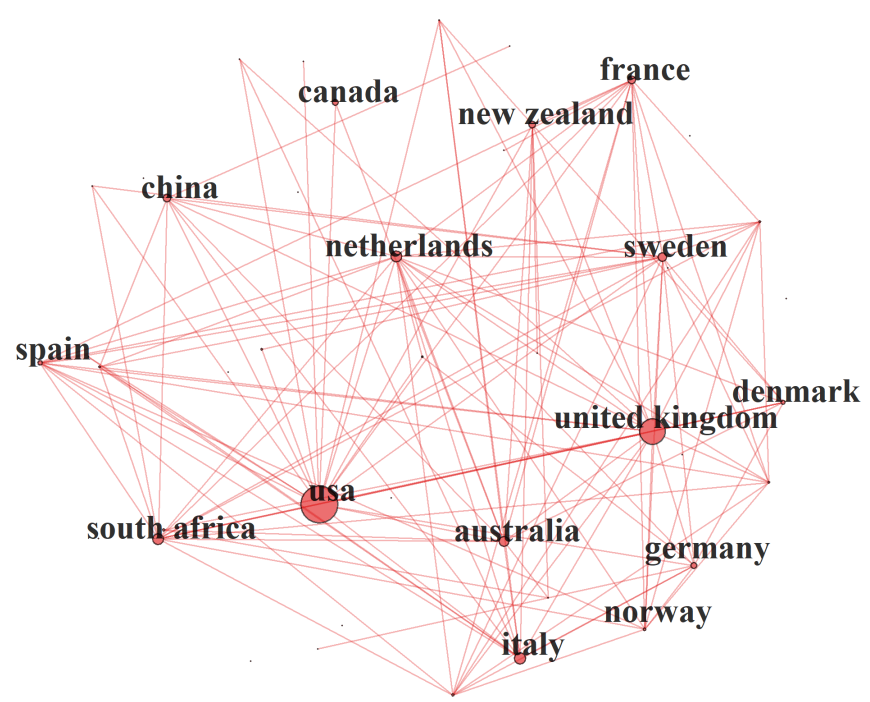

Fig. 4. Sentiment analysis of tweets posted about natural capital $(n=14,193)$.

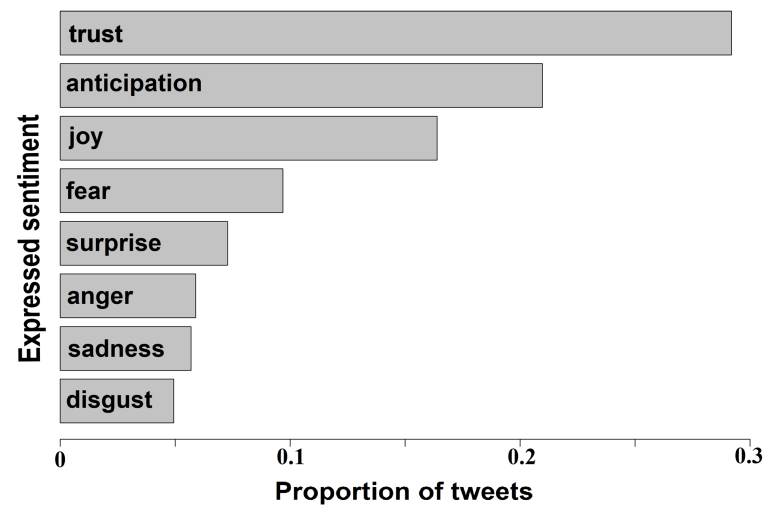

research boundaries. Furthermore, these ambitions can be supported by providing training workshops that aim to bridge the gaps between different disciplinary areas.

Outside academic publications, the network of Twitter users reflects which users are important influencers to those that are interested in natural capital. However, users may tweet about natural capital without necessarily using the phrase. We may have missed some tweets and have only obtained a portion of tweets by using the search term natural capital. Our results reveal that the Natural Capital Coalition's Twitter account is at the center of accounts that tweet frequently about natural capital. During the study period, the Natural Capital Coalition tweeted the most about natural capital. Although being an active tweeter can help 
raise the profile of a subject, being a prolific tweeter alone does not equate to an influential Twitter account.

We can explore the influence of a Twitter account using its follower to following ratio, which can be one indicator of success. It is generally assumed that accounts with higher numbers of followers have greater influence on Twitter compared to accounts that have less followers but follow more accounts (Grandjean 2016). A following/follower ratio that is closer to zero suggests higher influence than a ratio closer to one. The Natural Capital Coalition has 8582 followers and follows 2269 accounts, as of May 2019. This is a following/follower ratio of 0.26 , suggesting that the account has reasonable influence on Twitter.

In addition to the Natural Capital Coalition's Twitter presence, we can look at its history to determine its influence. In 2012, The Economics of Ecosystems and Biodiversity (TEEB) for Business Coalition was formed and this became the Natural Capital Coalition in 2014. The founding organizations were Institute of Chartered Accountants in England and Wales (ICAEW), Conservation International, Chartered Institute of Management Accountants, Corporate EcoForum, TEEB, FMO (Netherlands Development Finance Company), Global Initiatives, Global Reporting Initiative, International Federation of Accountants (IFAC), International Union for Conservation of Nature (IUCN), Accounting for Sustainability, The World Bank, World Business Council for Sustainable Development (WBCSD), and World Wildlife Fund (WWF). The Natural Capital Coalition is a unique collaboration that aims to improve and mainstream natural capital approaches, by joining together research organizations, businesses, and policy makers. Therefore, the Natural Capital Coalition is an important organization involved with natural capital, but it lies outside academic research. Because one of the Natural Capital Coalition's objectives is to mainstream natural capital thinking, its high presence on Twitter reflects its objectives.

The personal Twitter account that has the highest number of followers in the network plot is Jonathon Hughes (@JonnyEcology), who is the new head of the UN Environment World Conservation Monitoring Centre (UNEP-WCMC), previous CEO of the Scottish Wildlife Trust, and the cofounder of the World Forum on Natural Capital. He did not tweet the most about natural capital over the study period, but he is followed by many accounts that tweeted about natural capital. This indicates that Jonathon Hughes is a key influencer for other Twitter users interested in natural capital.

With the exception of @Taimur_T_Malik (New York), @ MichaleVardon (Australia), and @kaskadia (undetermined), the Twitter accounts in the network plot are all based in the UK. The likely reason is because the key account tweeting about natural capital, i.e., the Natural Capital Coalition, is a UK based organization. Our results suggest that the Natural Capital Coalition may have contributed to raising the profile of natural capital on Twitter, but predominantly in the UK.

Interestingly, most of the high-profile researchers in natural capital (i.e., present in Fig. 1a) do not have Twitter accounts. Possible reasons may be because they are already well known in their fields or they are uninterested in social media platforms and this might also be a generational issue. Robert Costanza is one of the few high-profile natural capital researchers with a Twitter account and he joined in 2014. Although he is highly influential within academia in the field of ecosystem services and natural capital, he only has 1233 followers on Twitter as of May 2019. This is compared to someone like Jonny Ecology, ex-Scottish Wildlife CEO, who has 9887 followers as of May 2019 and joined Twitter in 2010. This difference in followers can potentially be explained by their Twitter activity. Jonny Ecology posts approximately 2200 tweets per year, whereas Robert Costanza posts only around 36 tweets per year. A highly active Twitter account usually attracts more followers than a less active account.

\section{Crossing disciplines and subject areas}

Input from a range of disciplines is vital to improving natural capital research, and solutions cannot be provided by experts from any single discipline (Costanza and Kubiszewski 2012). Natural capital is not only a new field of research, but it is a method of framing current research from a new perspective and in a different context. It is a novel way of shaping the narrative of environmental protection, one that perhaps will have wider implications outside academic research.

Currently, one of the concerns regarding natural capital research is the perceived dominance of economic valuation (Jacobs et al. 2016, Hansjürgens et al. 2017). Our results suggest that natural capital is frequently associated with a range of subject areas and different words. Contrary to what might be expected from the wider perception of the term, the words "economic" or "valuation" do not dominate the keywords surrounding natural capital. In fact, our results reveal a range of subject areas associated with the term natural capital.

Natural capital is a growing field of interdisciplinary research that crosses the boundaries of ecology, environmental sciences, economics, and the social sciences. Many different research areas are represented on the word cloud for academic publications (Fig. 2 ), and they are all encompassed under the term natural capital. Therefore, natural capital can be a unifying concept that interlinks many current research areas within environmental sciences.

The word cloud shows that the term "ecosystem services" is the highest co-occurring keyword, followed by "biodiversity" and "conservation." Our results support the recent findings of a previous paper that explored publications in ecosystem services research (Droste et al. 2018). Ecosystem services, i.e., the benefits we receive from nature, is closely linked to natural capital, i.e., the stock natural resources. Hence, these two concepts often appear together within academic publications. This also highlights the fact that we need to emphasize the difference between natural capital and ecosystem services to avoid confusion, especially if they are frequently used in conjunction.

Natural capital is also associated with a range of keywords on Twitter. Accounting and business are among the top keywords associated with tweets on natural capital. The potential reason is because many industries and businesses have a Twitter presence, and they are becoming interested in the natural capital concept.

Using publication and social media data, we find that "ecosystem services" and "biodiversity" are important key words associated with natural capital. They are either the keywords for publications or they are found in the same tweet as natural capital. However, the words "natural" and "nature" are also associated with natural 
capital in tweets. In comparison, none of the researchers have used these two words as keywords in their publications. Words such as natural and nature are used more in the tweets than the word biodiversity, possibly indicating that they are better understood by nonacademic audiences. This result indicates that the choice of language to express a concept like natural capital can be important, depending on the target audience.

\section{Importance of international collaborations}

The country collaboration plot demonstrates that most countries seek coauthorships with American and British researchers, indicating that that these two countries are currently leading natural capital research. This can be explained with two potential reasons. Both countries developed as leading hubs for academic research and continue to provide significant investments into research. Furthermore, they are both English speaking countries so they have an advantage in academic publishing compared to non-native speaking countries (Corbera et al. 2016).

Nevertheless, there are many other countries depicted on the plot and natural capital research is not completely dominated by these two specific countries. There are collaborations between different countries around the world. Previous research has indicated that highly cited papers generally involve more coauthors and diverse international collaborations (Larivière et al. 2015). One potential explanation is that pressing scientific research issues are complex, so they require a range of researchers with differing expertise. Different countries can have different human and financial resources that contribute toward the research question. Increased international collaborations are important because protecting natural capital is a common challenge that needs to be urgently addressed globally, and requires input from plural perspectives and epistemologies (Smith et al. 2017).

International research collaborations can have more impact and advance natural capital research. Within natural capital research, a specific example that highlights the impact of international collaboration is between Zhiyun Ouyang (Chinese Academy of Sciences) and Gretchen Daily (Stanford University; leader of the Natural Capital Project). This long-term collaboration led to China's first national ecosystem assessment, which has been published in the journal Science (Ouyang et al. 2016). By collaborating internationally with China, Gretchen Daily's expertise in natural capital contributed to increased Chinese government investments into environmental conservation and increased impacts for natural capital research. International collaborations such as this can lead to novel and transformative research.

\section{Perceptions of natural capital}

Sentiment analysis allows us to gain an understanding of how a community perceives a certain subject such as natural capital. Twitter is a platform where people regularly express their opinions on issues, and this represents a relatively new area for sentiment analysis (Aroran and Rachna 2017). Twitter can provide insightful data on how natural capital is perceived by Twitter users, and opinions on the internet can affect future decisions of users (Martínez-Cámara et al. 2014).

Natural capital can be a controversial topic and can provoke strong personal opinions from both academics and nonacademics. The concept of placing a value on natural resources and using the word "capital," which is borrowed from economics, makes some people uncomfortable. Interestingly, our results indicate that the overall sentiment in tweets collected about natural capital is positive because most tweets were sorted into the categories trust or anticipation. Nevertheless, our results represent a limited sample of tweets and a longer time frame is required for further sentiment analysis regarding natural capital.

Sentiment analysis is not always accurate because of the complexity of language use, especially on the internet. Using sentiment analysis scores, we found the most positive tweet and the most negative tweet regarding natural capital:

It is mental health awareness week. Our natural environment plays such an important part in helping to improve our health and wellbeing. Places to enjoy the beauty, tranquility and wildlife.

Defining Earth's resources as natural capital is morally wrong, intellectually vacuous, and most of all counterproductive.

These two tweets suggest that the analysis has been successful in providing an approximate trend for the sentiments expressed in tweets. Interestingly, the two tweets accurately depict the debate surrounding natural capital. One side argues that natural capital can help to highlight the importance of nature (Costanza et al. 2017), whereas the other side believes that natural capital is counterintuitive to environmental protection (Silvertown 2016). The most negative tweet comes from a Guardian news article written by George Monbiot, who has 281,800 followers on Twitter, and he is a British writer famously against the concept of natural capital. This analysis shows that for controversial topics such as natural capital, researchers can use social media data to help gauge the general reaction to the topic using sentiment analysis.

\section{CONCLUSION}

We have explored natural capital using two different types of data, academic publications data and Twitter data. They can both provide quantitative insights to assess a topic of interest, and the use of such analyses has been relatively limited in relation to topics of interest to conservation. We have found an increase in natural capital publications and revealed the emergence of an epistemic community within natural capital research across three nodal networks. In addition, we identified potential collaboration disconnects between the three key research clusters working on natural capital.

Interdisciplinary research is needed to advance the natural capital approach, so research clusters would benefit from increased collaborations. This will lead to the emergence of a more encompassing community of practice around this term, especially one that draws on a more diverse range of disciplines. International collaboration between researchers can lead to more impactful research, as demonstrated by the collaboration between Stanford University and the Chinese Academy of Sciences. There should be increased engagement with academics from a broader range of countries.

Using Twitter data, we found a key network of 24 accounts that frequently post about natural capital. A range of different words are associated with natural capital tweets, but the words "natural," 
"biodiversity," and "nature" are most commonly associated. Natural capital can be a controversial subject that evokes personal opinions. Using sentiment analysis, we found that the overall tone of tweets about natural capital is positive. This helps us to understand how users perceive a subject emotionally.

In conclusion, the exclusivity of the communities in academic research and on Twitter suggest that the current communities surrounding natural capital are relatively small and specific, and there is no broad uptake of the concept observable yet. Therefore, further work is required for the wider acceptability of natural capital within both policy and practice around the world.

Responses to this article can be read online at: http://www.ecologyandsociety.org/issues/responses. $\mathrm{php} / 11118$

\section{LITERATURE CITED}

Abson, D. J., H. von Wehrden, S. Baumgärtner, J. Fischer, J. Hanspach, W. Härdtle, H. Heinrichs, A. M. Klein, D. J. Lang, P. Martens, and D. Walmsley. 2014. Ecosystem services as a boundary object for sustainability. Ecological Economics 103:29-37. https://doi.org/10.1016/j.ecolecon.2014.04.012

Aria, M., and C. Cuccurullo. 2017. bibliometrix: An R-tool for comprehensive science mapping analysis. Journal of Informetrics 11(4):959-975. https://doi.org/10.1016/j.joi.2017.08.007

Aroran, C., and Dr. Rachna. 2017. Sentiment analysis on Twitter data. International Research Journal of Engineering and Technology (IRJET) 14(6):31-36.

Bornmann, L., and R. Mutz. 2015. Growth rates of modern science: a bibliometric analysis based on the number of publications and cited references. Journal of the Association for Information Science and Technology 66(11):2215-2222. https:// doi.org/10.1002/asi.23329

Borrett, S. R., J. Moody, and A. Edelmann. 2014. The rise of network ecology: maps of the topic diversity and scientific collaboration. Ecological Modelling 293:111-127. https://doi. org/10.1016/j.ecolmodel.2014.02.019

Branch, T. A. 2013. Citation patterns of a controversial and highimpact paper: Worm et al. (2006) "Impacts of biodiversity loss on ocean ecosystem services.“ PLoS ONE 8(2):e56723. https:// doi.org/10.1371/journal.pone.0056723

Corbera, E., L. Calvet-Mir, H. Hughes, and M. Paterson. 2016. Patterns of authorship in the IPCC Working Group III report. Nature Climate Change 6(1):94-99. https://doi.org/10.1038/ nclimate2782

Costanza, R., R. de Groot, L. Braat, I. Kubiszewski, L. Fioramonti, P. Sutton, S. Farber, and M. Grasso. 2017. Twenty years of ecosystem services: How far have we come and how far do we still need to go? Ecosystem Services 28:1-16. https://doi. org/10.1016/j.ecoser.2017.09.008

Costanza, R., and I. Kubiszewski. 2012. The authorship structure of "ecosystem services" as a transdisciplinary field of scholarship.
Ecosystem Services 1(1):16-25. https://doi.org/10.1016/j. ecoser.2012.06.002

Csárdi, G., and T. Nepusz. 2006. The igraph software package for complex network research. Inter Journal, Complex Systems 1695.

Department for Environment Food \& Rural Affairs (Defra). 2018. 25 Year environment plan. Defra, London, UK. [online] URL: https://www.gov.uk/government/publications/25-year-environmentplan

Droste, N., D. D'Amato, and J. J. Goddard. 2018. Where communities intermingle, diversity grows - the evolution of topics in ecosystem service research. PLoS ONE 13(9):e0204749. https:// doi.org/10.1371/journal.pone.0204749

Dunlop, C. A. 2014. The possible experts: how epistemic communities negotiate barriers to knowledge use in ecosystems services policy. Environment and Planning C: Government and Policy 32(2):208-228. https://doi.org/10.1068/c13192j

Figueroa-Alfaro, R. W., and Z. Tang. 2016. Evaluating the aesthetic value of cultural ecosystem services by mapping geotagged photographs from social media data on Panoramio and Flickr. Journal of Environmental Planning and Management 60 (2):266-281. https://doi.org/10.1080/09640568.2016.1151772

Gentry, J. 2016. twitteR: R Based Twitter Client.

Gliozzo, G., N. Pettorelli, and M. Haklay. 2016. Using crowdsourced imagery to detect cultural ecosystem services: a case study in South Wales, UK. Ecology and Society 21(3):6. https://doi.org/10.5751/ES-08436-210306

Grandjean, M. 2016. A social network analysis of Twitter: mapping the digital humanities community. Cogent Arts \& Humanities 3:1171458. https://doi.org/10.1080/23311983.2016.1171458

Guerry, A. D., S. Polasky, J. Lubchenco, R. Chaplin-Kramer, G. C. Daily, R. Griffin, M. Ruckelshaus, I. J. Bateman, A. Duraiappah, T. Elmqvist, M. W. Feldman, C. Folke, J. Hoekstra, P. M. Kareiva, B. L. Keeler, S. Li, E. McKenzie, Z. Ouyang, B. Reyers, T. H. Ricketts, J. Rockström, H. Tallis, and B. Vira. 2015. Natural capital and ecosystem services informing decisions: from promise to practice. Proceedings of the National Academy of Sciences of the United States of America 112(24):7348-7355. https://doi.org/10.1073/pnas.1503751112

Hansjürgens, B., C. Schröter-Schlaack, A. Berghöfer, and N. Lienhoop. 2017. Justifying social values of nature: economic reasoning beyond self-interested preferences. Ecosystem Services 23:9-17. https://doi.org/10.1016/j.ecoser.2016.11.003

Hopke, J. E., and L. E. Hestres. 2018. Visualizing the Paris Climate Talks on Twitter: media and climate stakeholder visual social media during COP21. Social Media + Society 4 (3):205630511878268. https://doi.org/10.1177/2056305118782687

Jacobs, S., N. Dendoncker, B. Martín-López, D. N. Barton, E. Gomez-Baggethun, F. Boeraeve, F. L. McGrath, K. Vierikko, D. Geneletti, K. J. Sevecke, N. Pipart, E. Primmer, P. Mederly, S. Schmidt, A. Aragão, H. Baral, R. H. Bark, T. Briceno, D. Brogna, P. Cabral, R. De Vreese, C. Liquete, H. Mueller, K. S. H. Peh, A. Phelan, A. R. Rincón, S. H. Rogers, F. Turkelboom, W. Van Reeth, B. T. van Zanten, H. K. Wam, and C. L. Washbourn. 2016. A new valuation school: integrating diverse values of nature in resource 
and land use decisions. Ecosystem Services 22(Part B):213-220. https://doi.org/10.1016/j.ecoser.2016.11.007

Jockers, M. L. 2015. Syuzhet: extract sentiment and plot arcs from text.

Klein, J. T. 2008. Evaluation of interdisciplinary and transdisciplinary research. A literature review. American Journal of Preventive Medicine 35(2):S116-S123. https://doi.org/10.1016/ j.amepre.2008.05.010

Larivière, V., Y. Gingras, C. R. Sugimoto, and A. Tsou. 2015. Team size matters: collaboration and scientific impact since 1900. Journal of the Association for Information Science and Technology 66(7):1323-1332. https://doi.org/10.1002/asi.23266

Mace, G. M., K. Norris, and A. H. Fitter. 2012. Biodiversity and ecosystem services: a multilayered relationship. Trends in Ecology and Evolution 27(1):19-26. https://doi.org/10.1016/j.tree.2011.08.006

Martínez-Cámara, E., M. T. Martín-Valdivia, L. A. UreñaLópez, and A. R. Montejo-Ráez. 2014. Sentiment analysis in Twitter. Natural Language Engineering 20(1):1-28. https://doi. org/10.1017/S1351324912000332

Mitchell, P. H. 2005. What's in a name? Multidisciplinary, interdisciplinary, and transdisciplinary. Journal of Professional Nursing 21(6):332-334.

Mongeon, P., and A. Paul-Hus. 2016. The journal coverage of Web of Science and Scopus: a comparative analysis. Scientometrics 106(1):213-228. https://doi.org/10.1007/s11192-015-1765-5

Newman, T. P. 2017. Tracking the release of IPCC AR5 on Twitter: users, comments, and sources following the release of the Working Group I Summary for Policymakers. Public Understanding of Science 26(7):815-825. https://doi. org/10.1177/0963662516628477

Ouyang, Z., H. Zheng, Y. Xiao, S. Polasky, J. Liu, W. Xu, Q. Wang, L. Zhang, Y. Xiao, E. Rao, L. Jiang, F. Lu, X. Wang, G. Yang, S. Gong, B. Wu, Y. Zeng, W. Yang, and G. C. Daily. 2016. Improvements in ecosystem services from investments in natural capital. Science 352(6292):1455-1459. https://doi.org/10.1126/ science.aaf2295

Parsons, E. C. M., D. S. Shiffman, E. S. Darling, N. Spillman, and A. J. Wright. 2014. How Twitter literacy can benefit conservation scientists. Conservation Biology 28(2):299-301. https://doi.org/10.1111/cobi.12226

Peiffer, A., and M. Haustermann. 2018. Private sector \& natural capital: the business case for natural capital assessment. Global Nature Fund, Radolfzell, Germany. [online] URL: https:// naturalcapitalcoalition.org/private-sector-natural-capital-the-businesscase-for-natural-capital-assessment/

Robinson, D. A., N. Hockley, E. Dominati, I. Lebron, K. M. Scow, B. Reynolds, B. A. Emmett, A. M. Keith, L. W. de Jonge, P. Schjønning, P. Moldrup, S. B. Jones, and M. Tuller. 2012. Natural capital, ecosystem services, and soil change: why soil science must embrace an ecosystems approach. Vadose Zone Journal 11(1). https://doi.org/10.2136/vzj2011.0051
Silge, J., and D. Robinson. 2016. tidytext: Text mining and analysis using tidy data principles in R. Journal of Open Source Software 1(3):37. https://doi.org/10.21105/joss.00037

Silvertown, J. 2016. Ecologists need to be cautious about economic metaphors: a reply. Trends in Ecology \& Evolution 31 (5):336. https://doi.org/10.1016/j.tree.2016.03.007

Smith, A. C., P. A. Harrison, M. Pérez Soba, F. Archaux, M. Blicharska, B. N. Egoh, T. Erős, N. Fabrega Domenech, ÁI. György, R. Haines-Young, S. Li, E. Lommelen, L. Meiresonne, L. Miguel Ayala, L. Mononen, G. Simpson, E. Stange, F. Turkelboom, M. Uiterwijk, C. J. Veerkamp, and V. Wyllie de Echeverria. 2017. How natural capital delivers ecosystem services: a typology derived from a systematic review. Ecosystem Services 26:111-126. https://doi.org/10.1016/j.ecoser.2017.06.006

Tenerelli, P., U. Demšar, and S. Luque. 2016. Crowdsourcing indicators for cultural ecosystem services: a geographically weighted approach for mountain landscapes. Ecological Indicators 64:237-248. https://doi.org/10.1016/j.ecolind.2015.12.042

Unilever. 2018. Sustainable living. Unilever, London, UK. [online] URL: https://www.unilever.com/sustainable-living/reducingenvironmental-impact/natural-capital/

Vira, B., and W. M. Adams. 2009. Ecosystem services and conservation strategy: beware the silver bullet. Conservation Letters 2(4):158-162. https://doi.org/10.1111/j.1755-263X.2009.00063. $\underline{\mathrm{X}}$ 